\title{
Self-attitude and coping-strategies of children with eating disorders
}

\author{
Elena Yurievna Bakaeva, and Tatiana Sergeevna Pilishvili \\ Peoples' Friendship University of Russia
}

\begin{abstract}
Nowadays, the topic of eating behavior is becoming more and more popular. People with deviant forms of eating are described as mysterious "THEY" who deceive a lot in order to hide the true form of eating and deep feelings about this, are tyrants in their families, strive for perfection and are extremely difficult to treat. This paper focuses on the attitudes of patients with eating disorders and their habitual strategies for coping with stress behavior. The study is based on the question: are there differences in self-attitudes and coping strategies among adolescents with different eating behaviors?
\end{abstract}

\section{Introduction}

Disorder of the eating behaviour is a group of disorders characterized by anxiety and pathological belief in the presence of a significant physical disability, sometimes of a hypochondriacal nature, which the patient seeks to compensate through manipulation of his body, with particular attention to the issues of nutrition and calorie expenditure.

Anorexia nervosa is characterized by a conscious refusal to eat in order to correct, even at the cost of one's own life, one's "vice", which is often false. The disease can manifest itself both within an independent nosological unit and as an endogenous disease syndrome.

There are 4 stages of the course of the disease:

1. Initial, which is characterized by the so-called Korkina triad.

As a reason for discovering a hated defect in themselves, patients cite a painfully accepted reproach, a mockery of appearance or nutrition.

This stage is characterized by persistent dysmorphophobic and dysmorphomanic experiences - a feeling of self-rejection and actions aimed at correcting a "defect in appearance" through excessive physical exertion and strict diets.

2. Anorectic - it is characterized by a significant loss of body weight (up to 50 percent), the addition of secondary somato-endocrine disorders.

Depending on the premorbid personality traits, food deprivation, and the comorbidity of an eating disorder with affective pathologies, patients are either satisfied with their appearance or are convinced that it is necessary to continue to lose weight. Various pathological obsessions and fears regarding nutrition are relevant - fear of losing control over food intake, fear of gaining body weight, fear of painful sensations in the epigastric region after eating, etc. Behind them are rigid thoughts about titanic efforts over oneself, suffering in the pursuit of compensation for one's shortcomings, about an unbearable struggle against hunger and refusal to devalue them. 
3. Cachectic - at this stage, a lethal outcome is possible due to suicide, cardiac disorders, pneumonia, pulmonary edema, gastric perforations, internal bleeding and other intercurrent diseases. (L.I. Zakharova, 2019), (E.M. Solodovnik, L.A. Nepovinnykh, 2020).

Asthenic syndrome comes to the fore, patients are adynamic and emaciated.

4. Reduction of anorexia nervosa - with the slightest weight gain, dysmorphomanic experiences are again actualized.

Most authors studying eating disorders argue that patients with anorexia nervosa are characterized by the following emotional and personal characteristics: perfectionism, punctuality, scrupulousness, rigidity, high intelligence are expressed. The authors note that patients are emotionally immature and dependent individuals. ( V.V. Marilov, M.V. Korkina, A.M. Tsivilko, 1986 ), (M. Hirsch, 2018), (M. Woodman, 2011), (F. Alexander, 2017).

Bulimia nervosa is Greek for bovine hunger and is characterized by hyperphagic eating behavior. This disorder can manifest itself both within the framework of an independent borderline mental pathology, and within the framework of anorexia nervosa.

E.K. Kislova classifies bulimic behavior in anorexia nervosa as follows:

- Bulimia as a symptom of anorexia nervosa: patients experience intolerable hunger, but the fear of gaining body weight stops them from overeating, as a breakdown, one can see that patients chew food and spit it out;

- Bulimia as a stage of anorexia nervosa: occurs against the background of prolonged fasting, patients experience uncontrolled bouts of hunger, as a result of which there is a strong overeating followed by cleansing behavior. Obsessive fears of weight gain and body dysmorphic experiences are relevant;

- Bulimia as a variation of anorexia nervosa is formed in a short time after refusal to eat, as a response to unbearable fasting (E.K.Kislova, 2004), (G.F.Muzychenko, p.135).

Most modern authors consider eating disorder in terms of a biopsychosocial model. (Malkina-Pykh, 2007) It is believed that it is the combination of all three factors that forms this disease. It is about the following phenomena:

The biological factor considers eating behavior from the point of view of the need for nutrition and satisfying hunger, as a means of saturating the energy necessary to maintain the life and health of the individual. In addition, geneticists have found that all patients suffering from an eating disorder have similarities in the genetic code - the presence of a certain gene (HTR2A gene for serotonin receptor 5-HT2A, as well as gene for brain neutrophic factor (BDNF)).

Physiologists, for their part, argue that metabolic disturbances can also lead to the formation of deviant eating behavior. (A.O. Kibitov, G.E. Mazo, 2016)

The psychological factor opens up new facets of the possibility of considering the eating process. When eating, people enjoy themselves, reward or punish themselves, accept or hate themselves, build interpersonal contacts or avoid them. By developing different diets and diets in order to shape their body image, a person seeks recognition, acceptance, aesthetics and health. And it is amazing how self-deception is hidden behind the apparent self-care having developed a nutrition program and achieving real results in the form of a slimming body and approval from others, a person receives positive reinforcement of his actions and does not notice how his hobby turns into addiction. Obsessive fears of losing control over hunger and food intake, and gaining body weight become relevant. As a result, weight continues to decline to the degree of emanciation (cachexia). Obsessive thoughts about food, fear of eating and feelings of guilt for the eaten food are expressed. There are also obsessive actions in the form of constant measurement of the volume of one's body, daily weighing, purification behavior, which manifests itself in inducing vomiting after eating, and sometimes until the stomach is completely washed (vomiting till the transparent water). 
An interesting phenomenon of "confusion" in understanding one's physical and psychological state at the moment when the patient experiences negative emotions. We noticed that people with anorexia nervosa describe the state of satiety at the moment of experiencing frustration based on physicality - "an unpleasant feeling of satiety", "an obsessive desire to vomit", "abdominal fullness", "squeezing in the throat." It can be assumed that for patients with anorexia nervosa, the physiological feeling of satiety is identical to the emotional overflow of negative emotions.

It is important to note that patients with eating disorders are characterized by high rigidity, which manifests itself in stubbornness, obsession, difficulty in switching attention, difficulties in adapting to new conditions. We are inclined to assume that it is with this personality trait that the difficulty of correcting deviant eating behavior is associated.

Social factor.

In this context, it is relevant to characterize the influence of society on the mentality of the individual.

Fashion, as a social factor, imposes its ideals on us. "If I do not match, then I will not be accepted." An adolescent with a "neurotic" form of perfectionism, in the terminology of Hamachek (N.G. Garanyan, 2006), begins to do everything to become accepted by society, to become perfect. He strives for model forms, for the maximum achievements of his activities, as a result, he becomes a prisoner of his own high requirements. In his pursuit of perfection, an adolescent can no longer independently break out of the rigid framework. Thus, a person turns into a robot, exhausted and has no room for error. Consequently, food addiction is formed on the basis of low adaptation in society, emotional immaturity and pathological rigidity of the patient.

It is impossible not to note religious views and their possible influence on the formation of eating behavior. According to the works of A. Freud, self-restraint, refusal to eat is symbolic of fasting of repentance, cleansing from sins, asceticism. If you try to analyze the relationship of this protective mechanism with religion, then the following points draw your attention: during the monthly period, a woman is prohibited from entering the church, she is considered "dirty". It can be assumed that growing up, healthy work of the reproductive system and, as a consequence, the appearance of sexual impulses are the "vices" of women, which the spiritual world denies. The child is considered by church canons as a pure being, for whom the road to Paradise is open. The relationship is seen that the child is accepted and clean, the adult woman is judged and "dirty". Therefore, the way to maintain acceptance of the church is to refuse to grow up or to "wash away sins" through self-sacrifice. For a deeper understanding, let us quote the words of a priest of a Moscow church: "the martyrs suffered and ended up in Paradise, so we must humble ourselves and accept our fate."

Based on the above, it is clear that patients with an eating disorder have a low degree of adaptation and displace, and perhaps forbid themselves to experience and express negative emotions.

The aim of this work is to study ways of coping with stress behavior and characteristics of self-attitude in patients of pubertal age with different eating behaviors.

We hypothesized that there are significant differences in the characteristics of selfattitude and coping strategies that adolescent girls with different eating behaviors resort to in anxious situations.

The results obtained can be used in the development of group psychotherapeutic programs aimed at correcting self-attitude in patients with eating disorders, as well as developing constructive coping strategies under stress conditions.

In the presented work, we conducted a study in which 3 groups of respondents aged 1617 years took part:

- 21 people - girls with restrictive eating behavior (diagnosed with anorexia nervosa), $\mathrm{BMI} \leq 17.5$; 
- 20 people - girls with an external and emotiogenic type of eating behavior, $20.5 \leq$ $\mathrm{BMI} \leq 32$;

- 20 people - girls with a harmonious type of eating behavior, $18.5 \leq \mathrm{BMI} \leq 25$.

The study was carried out on the basis of the children's gynecological department of the Federal State Budgetary Institution National Medical Research Center for Obstetrics, Gynecology and Perinatology named after V.I. Academician V.I. Kulakov of the Ministry of Health of the Russian Federation.

The following psychodiagnostic techniques were used for the study:

1. Questionnaire of coping strategies (coping strategies) by R. Lazarus, S. Folkman (adaptation by T. L. Kryukova, E. V. Kuftyak, M.S. Zamyshlyaeva;

2. The scale of self-attitude of V. Stolin-S. Panteleev.

With the subsequent application of methods of mathematical and statistical data processing (comparative analysis - Mann Whitney U-test).

\section{Results of the conducted empirical research}

The results of coping behavior diagnostics are shown in Figure 1 (mean values).

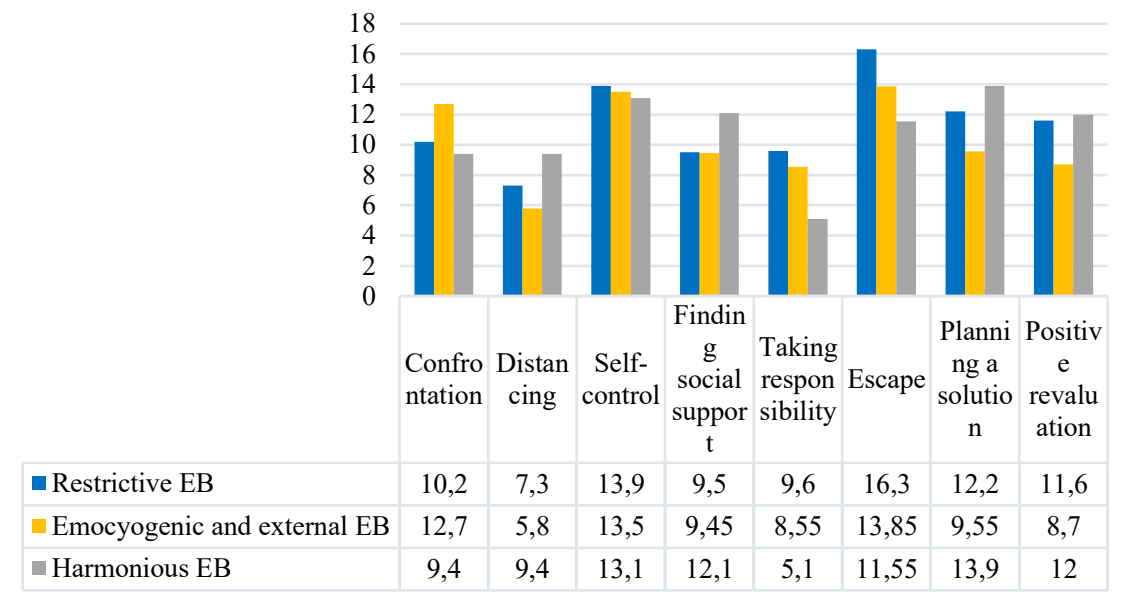

Fig. 1. Results of diagnostics of coping strategies in girls with different eating behaviors.

Figure 1 shows that in the group of girls with restrictive behavior strategies of escape and self-control prevail, while distancing is expressed in them to the least degree. Hence, when faced with difficulties, girls with anorexia nervosa tend to avoid solving the problem, control their emotions and behavior, while attempts to overcome negative experiences in connection with the problem due to a subjective decrease in the significance of the problem are not typical for them.

In the group of girls with hyperphagic behavior, a high level of severity of escape and self-control strategies is observed, while distancing is the least characteristic of them. This indicates that in difficult situations, they tend to avoid solving problems and over-control their emotions and behavior, while overcoming the problem by reducing its importance is not typical for them ...

In the group of girls with harmonious eating behavior, the strategies of planning problem solving and self-control are most pronounced, while the acceptance of responsibility is expressed to the least degree. This suggests that in difficult situations, they seek to find a real way out of the situation and control their emotions, while underestimating their contribution to the occurrence of the problem may be observed. 
Thus, girls with anorexia nervosa, as well as girls with bulimic eating behavior, are distinguished by the predominance of escape and self-control strategies, while the strategy of distancing is expressed in them to the least degree. For girls with harmonious eating behavior, the predominance of strategies for planning problem solving and self-control is characteristic, and the strategy of taking responsibility is expressed in them to the least degree.

Let's analyze the features of self-attitude in groups. Figure 2 shows the distribution of respondents by the level of the integral indicator of self-attitude.

\section{Integral indicator of self-attitude}

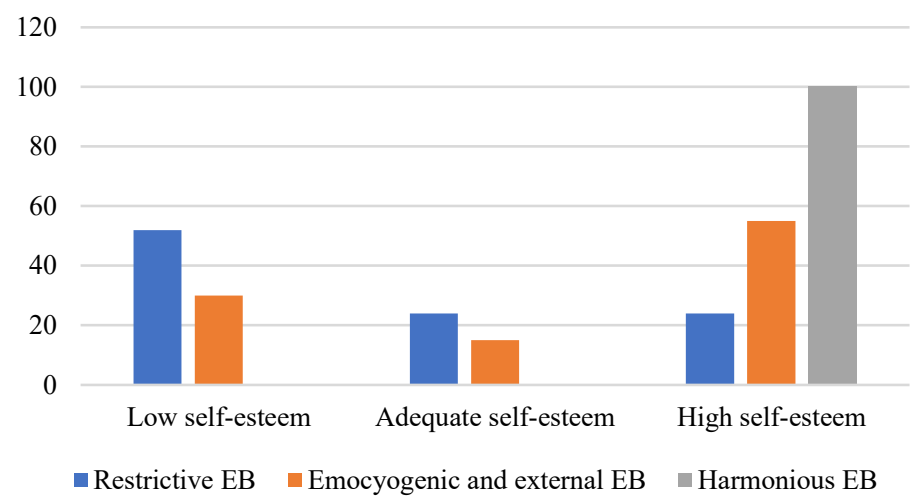

Fig. 2. Distribution of girls with different eating behavior according to the level of the integral indicator of self-attitude.

In the group of girls with a restrictive type of eating behavior, an underestimated level of self-esteem prevails (52\%), while an equal number of respondents $(24 \%)$ have adequate selfesteem and an overestimated level. This indicates that most girls have problems with selfesteem, manifested in inadequate self-esteem.

In the group of girls with hyperphagic eating behavior, $55 \%$ of the surveyed have an overestimated level of self-esteem, $30 \%$ are characterized by an underestimated level, and $15 \%$ have an adequate level. This suggests that this group is also dominated by girls with negative features of self-attitude.

In the group of girls with a harmonious type of eating behavior, $100 \%$ have an overestimated self-esteem. This suggests that they are characterized by an inadequate attitude towards themselves, which consists in an inadequately overestimated assessment of their qualities and abilities.

Thus, in the group of girls with anorexia nervosa, an underestimated level of self-esteem prevails, for girls with bulimic form of eating behavior overestimated self-esteem is most characteristic, and girls with harmonious eating behavior also have an overestimated selfesteem.

In the course of processing the research results, we carried out a comparative analysis of coping strategies and self-esteem features in groups of adolescents with different eating behaviors using the Mann-Whitney U-criterion.

The results obtained demonstrate statistically significant differences both in the methods of coping with stress and in the characteristics of self-esteem in groups of adolescents with various forms of eating behavior. 


\subsection{Description of the results of a comparative analysis of coping strategies in adolescents with different types of eating behavior}

\subsubsection{In a comparative analysis of coping strategies in groups of adolescents with restrictive and hyperphagic eating behavior, the following results were obtained:}

- The CONFRONTATION indicator is significantly higher in the group of girls with emotiogenic and external types of eating behavior $(\mathrm{U}=77.5, \mathrm{p}=000.1$, cf. rank in group 1 $=14.69$, cf. rank in group $2=27.63$ ). Consequently, girls with hyperphagic eating behavior in a difficult situation more often respond with high behavioral activity, including those aimed at changing the situation, than girls with anorexia nervosa. It may be connected with the fact that for adolescents who are prone to excessive food restriction, active activity in stress situations is extremely energy-intensive, because aggravates the depletion of the body, which makes this strategy a little typical for them.

- The indicator ACCEPTANCE OF RESPONSIBILITY is significantly higher in the group of girls with a restrictive type of eating behavior $(\mathrm{U}=130.5, \mathrm{p}=0.035$, compare rank in group $1=24.79$, compare rank in group $2=17.04$ ). Consequently, girls with anorexia nervosa are more likely to respond with excessive self-criticism in difficult situations than girls in the other group. This is probably due to the fact that girls with anorexia use excessive self-accusation as punishment, with which they justify inadequate food restriction.

- The "Escape" indicator is significantly higher in the group of girls with a restrictive type of eating behavior $(U=84.5, p=0.001$, compare rank in group $1=26.98$, compare rank in group $2=14.7$ ). This suggests that girls with a restrictive type of behavior tend to avoid solving problems more often than girls with hyperphagic eating behavior. This is probably due to the fact that girls of the first group are distinguished by a large subjective feeling of helplessness, formed against the background of prolonged exhaustion.

- The indicator PLANNING A SOLUTION TO THE PROBLEM is significantly higher in the group of girls with a restrictive type of eating behavior $(U=58, p=0.001$, compare rank in group $1=28.24$, compare rank in group $2=13.4$ ). This suggests that girls in the first group in a stressful situation are more often directed at planning actions to solve the problem than girls in the second group. This can be explained by the fact that in girls with bulimic type of eating behavior, emotional response prevails over rational understanding of the situation, and therefore coping strategies that imply a rational approach are less typical for them.

- The "Positive overestimation" indicator is significantly higher in the group of girls with a restrictive type of eating behavior $(\mathrm{U}=58.5, \mathrm{p}=0.001$, compare rank in group $1=$ 28.21 , compare rank in group $2=13.3$ ). This suggests that girls with anorexia are more likely to positively rethink a stressful situation than girls in the second group. This is probably due to the fact that girls with a restrictive type of eating behavior justify their food restrictions by striving for self-development, due to which they perceive stressors as an opportunity to approach their ideal image of a strong-willed, strong person.

\subsubsection{In a comparative analysis of the peculiarities of coping strategies in girls with restrictive and harmonious eating behavior, the following results were obtained:}

- The "Distancing" indicator is significantly higher in the group of girls with a harmonious type of eating behavior $(\mathrm{U}=119, \mathrm{p}=0.016, \mathrm{M} 1=16.6, \mathrm{M} 2=25.5)$. It turns out that girls with a harmonious type of eating behavior in a difficult situation tend to reduce its importance more often than adolescents with a restrictive type of eating behavior. This is 
probably due to the fact that girls with anorexia are characterized by pronounced rigidity, which makes it difficult for them to switch from a stressful situation to other stimuli.

- The indicator "Search for social support" is significantly higher in the group of girls with a harmonious type of eating behavior $(\mathrm{U}=76, \mathrm{p}=0.001, \mathrm{M} 1=14.6, \mathrm{M} 2=27.7)$. Consequently, girls with harmonious eating behavior more often in a difficult situation resort to the search for social resources to solve it than adolescents of the first group. This is probably due to the fact that girls with anorexia have a lower level of social adaptation: due to a negative attitude towards themselves, they expect the same attitude from others, which causes them to strive for isolation.

- The indicator "Acceptance of responsibility" is significantly higher in the group of adolescents with a restrictive type of eating behavior $(\mathrm{U}=5.5, \mathrm{p}=0.001, \mathrm{M} 1=30.7, \mathrm{M} 2=$ 10.7). It turns out that girls with anorexia are more likely to react with excessive self-criticism in difficult situations than respondents from the other group. This is probably due to the fact that adolescents with a restrictive type of eating behavior, due to low self-esteem, are characterized by high self-accusation, i.e. they blame themselves rather than other people or circumstances for any problems that arise.

- The Runaway indicator is significantly higher in the group of girls with a restrictive type of eating behavior $(\mathrm{U}=20, \mathrm{p}=0.001, \mathrm{M} 1=30.05, \mathrm{M} 2=11.5)$. Consequently, adolescents with anorexia tend to avoid problem solving more often than respondents with harmonious eating behavior. This is probably due to the fact that girls of the first group are distinguished by a great subjective feeling of helplessness, and any stressful situations cause severe manifestations of mental exhaustion in them, which makes them avoid them.

- The indicator "Planning a solution to the problem" is significantly higher in the group of adolescents with a harmonious type of eating behavior $(\mathrm{U}=78.5 \mathrm{p}=0.001, \mathrm{M} 1=$ $14.7, \mathrm{M} 2=27.5)$. This suggests that girls of the second group in a stressful situation are more often directed at planning actions to solve the problem than adolescents of the first group. This is probably due to the fact that girls with a harmonious type of eating behavior are distinguished by a more realistic vision of the situation and a positive approach to it, while patients with anorexia see the problem as clearly hopeless.

\subsubsection{As a result of a comparative analysis of the peculiarities of coping strategies in adolescents with hyperphagic and harmonious eating behavior, the following results were obtained:}

- The "Confrontation" indicator is significantly higher in the group of girls with bulimic symptoms $(\mathrm{U}=36, \mathrm{p}=0.001, \mathrm{M} 1=28.7, \mathrm{M} 2=12.3)$. It turns out that girls of the first group are more inclined to respond with non-targeted behavioral activity in stressful situations. This is probably due to the fact that hyperphagous eating behavior is formed on the basis of impulsivity, which is also true for the strategy of confrontation.

- The indicator "Distancing" is significantly higher in the group of girls with a harmonious type of eating behavior $(\mathrm{U}=34, \mathrm{p}=0.001, \mathrm{M} 1=12.2, \mathrm{M} 2=28.8)$. Consequently, adolescents with a harmonious type of eating behavior in a difficult situation tend to reduce its importance more often than respondents with an emotiogenic and external type of eating behavior. This is probably due to the fact that girls of the first group are characterized by increased emotional reactivity, as a result of which the strategies for reducing the significance of the problem due to intellectual efforts turn out to be inoperative for them.

- The indicator "Search for social support" is significantly higher in the group of adolescents with a harmonious type of eating behavior $(\mathrm{U}=43, \mathrm{p}=0.001, \mathrm{M} 1=12.6, \mathrm{M} 2=$ 28.3). It turns out that respondents with a harmonious type of eating behavior more often in a difficult situation resort to looking for social resources to solve it than girls of the first group. This is probably due to the fact that adolescents with hyperphagic eating behavior 
have a lower level of social adaptation associated with the expectation of a negative assessment from others.

- The indicator "Acceptance of responsibility" is significantly higher in the group of girls with bulimic type of eating behavior $(\mathrm{U}=6.5, \mathrm{p}=0.001, \mathrm{M} 1=30.1, \mathrm{M} 2=10.8)$. This suggests that girls with hyperphagic eating behavior are more likely to react with excessive self-criticism in difficult situations than adolescents from the other group. This is probably due to the fact that the respondents of the first group are more prone to self-accusation reactions, formed as a response to compulsive overeating.

- The "Escape" indicator is significantly higher in the group of girls with emotiogenic and external types of eating behavior $(\mathrm{U}=75, \mathrm{p}=0.001, \mathrm{M} 1=26.7, \mathrm{M} 2=14.2)$. Consequently, adolescents of the first group tend to avoid solving problems more often than girls with harmonious eating behavior. This is probably due to the fact that the respondents of the first group are more likely to have a negative perception of themselves and the world around them, as a result of which they do not believe in their ability to resolve life difficulties.

- The indicator "Planning a solution to the problem" is significantly higher in the group of girls with a harmonious type of eating behavior $(U=9 \mathrm{p}=0.001, \mathrm{M} 1=10.9, \mathrm{M} 2=$ 30.05). Consequently, the adolescents of the second group in a stressful situation are more often directed at planning actions to solve the problem than the respondents of the first group. This is probably due to the fact that girls with a harmonious type of eating behavior are distinguished by a more realistic vision of the situation and a positive approach to it, while patients with eating disorders are characterized by a negative outlook on the problem and a belief in its insolubility.

- The "Positive overestimation" indicator is significantly higher in the group of adolescents with a harmonious type of eating behavior $(\mathrm{U}=48 \mathrm{p}=0.001, \mathrm{M} 1=12.9, \mathrm{M} 2$ $=28.5$ ). This means that girls with harmonious eating behavior are more likely to perceive difficulties as stimuli for personal growth than girls from the other group. This is probably due to the fact that girls with emotional and external eating behavior as a result of the predominance of a negative emotional background more often see the problem as a hindrance to their activity, ignoring the possible experience that it carries.

\subsection{Description of the results of a comparative analysis of the characteristics of self-attitude in adolescents with different types of eating behavior}

\subsubsection{In a comparative analysis of the characteristics of self-attitude in adolescents with restrictive, emotional and external eating behavior, the following data were obtained:}

- $\quad$ in terms of self-attitude indicators "Self-esteem" $(\mathrm{U}=117.5 \mathrm{p}=0.015$, average rank in group $1=16.6$, average rank in group $2=25.63)$, "Self-interest" $(U=131 \mathrm{p}=0.034$, average rank in group $1=17.2$, average rank in group $2=24.9)$ and "Self-understanding" (U $=107.5, \mathrm{p}=0.006$, compare rank in group $1=16.1$, cf. rank in group $2=26.13$ ), the level of which is higher in girls with a hyperphagic type of eating behavior. Consequently, respondents with emotional and external eating behavior have a more positive attitude towards themselves than adolescents of the second group. This is probably due to the fact that patients with anorexia have more pronounced high demands on themselves and excessive striving to meet certain ideals, which does not give the opportunity to enjoy their own activities, causes constant dissatisfaction with themselves and contributes to a decrease in self-esteem. Presumably, girls with anorexia nervosa find it more difficult to overcome imposed ideals due to their high rigidity. 
2.2.2 In a comparative analysis of the characteristics of self-attitude in adolescents with restrictive and harmonious eating behavior, significant differences are observed in all indicators of self-attitude:

- $\quad$ "Integral self-attitude" $(\mathrm{U}=15.5, \mathrm{p}=0.001, \mathrm{M} 1=11.7, \mathrm{M} 2=30.7)$;

- $\quad$ "Self-esteem" ( $\mathrm{U}=19, \mathrm{p}=0.001, \mathrm{M} 1=11.9, \mathrm{M} 2=30.5)$;

- $\quad$ "Selfsympathy" ( $\mathrm{U}=12.5 \mathrm{p}=0.001, \mathrm{M} 1=11.6, \mathrm{M} 2=30.88)$;

- $\quad$ "General expected attitude towards oneself" $(\mathrm{U}=52, \mathrm{p}=0.001, \mathrm{M} 1=13.4, \mathrm{M} 2=$ 28.9);

- “General self-interest" $(\mathrm{U}=46, \mathrm{p}=0.001, \mathrm{M} 1=13.1, \mathrm{M} 2=29.2)$;

- $\quad$ "Self-confidence" $(\mathrm{U}=66.5, \mathrm{p}=0.001, \mathrm{M} 1=14.1, \mathrm{M} 2=28.1)$;

- $\quad$ "Expected attitude" $(\mathrm{U}=83.5, \mathrm{p}=0.001, \mathrm{M} 1=14.9, \mathrm{M} 2=27.33)$;

- $\quad$ "Self-acceptance" ( $\mathrm{U}=2.5, \mathrm{p}=0.001, \mathrm{M} 1=11.1, \mathrm{M} 2=31.3)$;

- $\quad$ "Self-guidance" ( $\mathrm{U}=102, \mathrm{p}=0.003, \mathrm{M} 1=15.8, \mathrm{M} 2=26.4)$;

- $\quad$ "self-accusation" ( $\mathrm{U}=27.5, \mathrm{p}=0.001, \mathrm{M} 1=29.6, \mathrm{M} 2=11.88)$;

- $\quad$ "Self-interest" $(\mathrm{U}=33, \mathrm{p}=0.001, \mathrm{M} 1=12.5, \mathrm{M} 2=29.8)$;

- $\quad$ "Self-understanding" $(\mathrm{U}=25, \mathrm{p}=0.001, \mathrm{M} 1=12.1, \mathrm{M} 2=30.2)$.

The differences indicate that adolescents with harmonious eating behavior have a more positive self-attitude than patients with anorexia. This is probably due to the fact that negative self-attitude is a risk factor for the formation of eating disorders: against the background of an inadequate attitude towards oneself, the need for acceptance grows, which is achieved through the desire to achieve ideals.

2.2.3 In a comparative analysis of the characteristics of self-attitude in adolescents with hyperphagic and harmonious eating behavior, significant differences were found in the following indicators of self-attitude:

- $\quad$ "Integral self-attitude" $(\mathrm{U}=12, \mathrm{p}=0.001, \mathrm{M} 1=11.1, \mathrm{M} 2=29.9)$;

- $\quad$ "Self-esteem" ( $\mathrm{U}=38 \mathrm{p}=0.001, \mathrm{M} 1=12.4, \mathrm{M} 2=28.6)$;

- $\quad$ "Self-sympathy" ( $\mathrm{U}=12 \mathrm{p}=0.001, \mathrm{M} 1=11.1, \mathrm{M} 2=29.9)$;

- $\quad$ "General expected attitude towards oneself" $(\mathrm{U}=14.5, \mathrm{p}=0.001, \mathrm{M} 1=11.2, \mathrm{M} 2=$

29.7);

- “General self-interest” $(\mathrm{U}=43.5, \mathrm{p}=0.001, \mathrm{M} 1=12.6, \mathrm{M} 2=28.33)$;

- $\quad$ "Self-confidence" $(\mathrm{U}=57, \mathrm{p}=0.001, \mathrm{M} 1=13.3, \mathrm{M} 2=27.65)$;

- $\quad$ "Expected attitude" ( $\mathrm{U}=74.5, \mathrm{p}=0.001, \mathrm{M} 1=14.2, \mathrm{M} 2=26.7)$;

- $\quad$ "Self-acceptance" $(\mathrm{U}=2, \mathrm{p}=0.001, \mathrm{M} 1=10.6, \mathrm{M} 2=30.4)$;

- "Self-accusation" $(\mathrm{U}=32.5, \mathrm{p}=0.001, \mathrm{M} 1=28.8, \mathrm{M} 2=12.1)$;

- $\quad$ "Self-interest" $(\mathrm{U}=16, \mathrm{p}=0.001, \mathrm{M} 1=11.3, \mathrm{M} 2=29.7)$;

- $\quad$ "Self-understanding" $(\mathrm{U}=82.5, \mathrm{p}=0.001, \mathrm{M} 1=14.6, \mathrm{M} 2=26.3)$.

The revealed differences indicate that the parameters of self-attitude are more favorable in the group of adolescents with a harmonious type of eating behavior. This is probably due to the fact that girls with a hyperphagic type of eating behavior, due to bouts of overeating and the inability to cope with negative emotions in a different way, feel their inferiority, which is aggravated by the inability to positively interact with the environment due to fear of evaluation. 


\section{Conclusion}

As a result of the study, we came to the conclusion that there are statistically significant differences in the characteristics of self-esteem and coping strategies in puberty children with different eating behaviors.

It was found that adolescents with an eating disorder are more likely to resort to nonconstructive coping strategies in a difficult situation for them - escape and self-control. It is worth noting the following features:

- the group of patients with anorexia nervosa is most characterized by coping strategies of taking responsibility and escape.

- the group of adolescents with hyperphagic eating behavior uses the coping strategy of confrontation more often than others.

- the group of respondents with harmonious eating behavior more often than others resort to the strategy of distancing, planning a solution to the problem and positive overestimation.

With regard to self-esteem, we came to the conclusion that all three groups of adolescents have inadequate forms of it, but there are significant differences:

- adolescents with anorexia nervosa have low self-esteem. These patients are dominated by exaggerated demands on themselves, striving for ideality, and each discrepancy deeply wounds and strikes a blow to the image of the "I", which probably causes the need to punish oneself with hunger;

- $\quad$ girls with hyperphagic eating behavior have a more positive attitude towards oneself than patients with restrictive eating behavior. It should be noted that this group of respondents hides vulnerability and emotional immaturity behind the external overestimated self-esteem. It can be assumed that these adolescents have a desire to seize their experiences and against the background of overeating, the inability to break the pathological circle, they experience a feeling of inferiority, which entails a new attack of filling themselves with food.

- respondents with harmonious eating behavior also showed a positive attitude towards themselves and overestimated self-esteem, manifested in an excessively high and not always justified assessment of their qualities and capabilities.

\section{References}

1. V. V. Marilov, M. V. Korkina, A. M. Tsivilko, Anorexia nervosa, 176 (1986)

2. G. F. Muzychenko, Projective method "Non-existent animal". Guidance and results of psychodiagnostic research of adult patients with various disorders of the emotional and personal sphere, 556 (2013)

3. A. O. Kibitov, G. E. Mazo, Social and Clinical Psychology (2016)

4. I. G. Malkina-Pykh, Eating behavior therapy, 1040 (2007)

5. N. G. Garanyan, Difficult Patient Journal for Physicians (2006)

6. M. Hirsch, "This is my body ... and I can do with it whatever I want": A psychoanalytic view of dissociation and body dramatization, 381 (2018)

7. F. Alexander, Psychosomatic medicine. Principles and application, 250 (2017)

8. E. K. Kislova, Bulimic disorders in anorexia nervosa (2004)

9. E. Wufong, P. Rhodes, J. Conti, Journal of Eating Disorders, 7, 5 (2019) 